\title{
Phytochemical Analysis and Antimicrobial Activities of Different Callus Extracts of Pelargonium Sidoides DC. Against Food Borne Pathogenic Bacteria
}

\author{
Mona M. Ibrahim ${ }^{1 *}$, Salem Abd El Ghani', Sherein I. Abd El-Moez ${ }^{3}$ \\ ${ }^{1}$ Plant Biotechnology Department, Genetic Engineering \& Biotechnology Division, National Research Centre, Dokki, Giza, Egypt. \\ ${ }^{2}$ Dairy Science Department, Food Industries and Nutrition Division, National Research Center, Dokki, Giza, Egypt. \\ ${ }^{3}$ Department of Microbiology and Immunology, Veterinary Research Division, National Research Center, Dokki, Giza, Egypt.
}

\section{ARTICLE INFO \\ Article history: \\ Received on: 07/01/2018 \\ Accepted on: 19/02/2018 \\ Available online: 29/04/2018}

\section{Key words:}

Pelargonium sidoides,

Callus growth,

Phytochemical analysis,

Antimicrobial activities.

\begin{abstract}
The objective of our study was to evaluate the secondary metabolites produced from callus culture of Pelargonium sidoides. This study was performed to, 1) evaluate the growth of Pelargonium sidoides DC. calli derived from different explants (leaf, root, and shoot tip), 2) to determine total phenolic, flavonoids and proanthocyanidin contents in aqueous methanol, water and aqueous acetone extracts of calli from different explants. Moreover, the antimicrobial activities of different extracts against food borne diseases caused by pathogenic bacteria were studied. The medium which contained $1.0 \mathrm{mg} / \mathrm{l} \alpha$-naphthalene acetic acid and $0.2 \mathrm{mg} / \mathrm{l} \mathrm{Kinetin}$ was best to get friable calli with little brown deposits. The highest phenolic content was in calli from root extracted with aqueous acetone followed by calli from shoot tip extracted with the same solvent (12.34 and $4.78 \mathrm{mg} / \mathrm{g} \mathrm{DW})$ respectively. Also, the highest values of flavonoids content $(20.82 \mathrm{mg} / \mathrm{g} \mathrm{DW})$ and Proanthocyandins $\left(0.290 \mathrm{~A}_{550} \mathrm{~nm} / \mathrm{mg}\right)$ were recorded with calli from root extracted with aqueous acetone. Antimicrobial effect of different calli extracts showed the maximum inhibition zone diameter $(35 \mathrm{~mm})$ was recorded with callus from shoot tip explants extracted with aqueous acetone against Clostridium perfringens ATCC.
\end{abstract}

\section{INTRODUCTION}

Pelargonium species family, Geraniaceae are predestined for their colorful garish flowers and odd leaf shapes (Wojtania et al., 2004). Pelargonium species have contributed decidedly to the annual industry in North America and Europe, which is account an estimated $\$ 700$ million annually (Mithila et al., 2001). The essential oils of Pelargonium species are in high request in the pharmaceutical, aromatherapy, perfumery and cosmetic industries because of different phytochemical property. The aerial parts of these Pelargonium species are active as wound healing agents (Kolodziej, 2000).

Casting of the roots of Pelargonium sidoides DC. and Pelargonium reniforme Curt. accept been acclimated to

\footnotetext{
${ }^{*}$ Corresponding Author

Mona M. Ibrahim, Plant Biotechnology Department, Genetic Engineering \& Biotechnology Division, National Research Centre, Dokki, Giza, Egypt.E-mail:monaibrahem27@yahoo.com
}

amusement coughs, chest problems including tuberculosis and gastrointestinal disorders such as diarrhea and dysentery. Aside from, these plant materials alleged to accommodate a cure for hepatic disorders and dysmenorrheal. Studies accept advised the anti-tuberculosis, antibacterial, and antifungal action of two Pelargonium species (Kolodziej, 2000; Latté and Kolodziej, 2000; Kolodziej et al., 2003; Mativandlela et al., 2006). Mativandlela et al. (2007) stated the isolation, identification, and antitubercular action of the compounds acquired from the butanol fraction of $P$. sidoides DC. They isolated and identified the six compounds: coumarins (umckalin, scopoletin, 6,8-dihydroxy5.7-dimethoxy-2H-benzopyran-2-one, and 6,8-dihydroxy-7methoxy-2H-benzopyran-2-one) and flavonoids (catechin and epigallocatechin). These isolated compounds were estimated as an anti-tubercular activity with Mycobacterium smegmatis and Mycobacterium tuberculosis.

Seeds and cuttings are the main propagation methods for most Pelargonium species (Wojtania et al., 2004). Plant 
tissue culture techniques can be used to get a large number of plants species for preservation and upgrade target. Studies on plant metabolites obtaining by using callus cultures have been accomplished on the large scale since the end of the 1950's. Such culturing technique is used for secondary metabolites production like hormones, enzymes, proteins, antigens, food additives and natural pesticides, these active compounds are used for pharmaceuticals and cosmetics (Terrier et al., 2007). Duchow et al. (2014) found that the blend of dichlorophenoxy acetic acid $(2,4-\mathrm{D})$ and kinetin (Kin) together gives rise to excellent growth for calli but with browning formation, even though the calli which induced on the medium containing both 6-benzylaminopurine (BAP) and naphthalene acetic acid (NAA) obtained rapid growth with a few browning formation. The combination of NAA and Kin was used for induction calli from only petioles resulted in calli with crumbly consistency (Moyo et al., 2012). Prosperous callus induction from leaves, stems, and seeds of $P$. sidoides was first achieved on the medium containing 2,4-D and Indole-3-butyric acid (IBA) (Lewu et al., 2007). Therefore, the aim of this work was to study to produce some secondary metabolites (phenolics, flavonoids, and proanthocyanidins) in callus cultures of $P$. sidoides derived from different explants. The effect of solvent type on the contents of these metabolites was highlighted. The antimicrobial activity of the different extracts obtained from different explants calli were tested against food borne poisoning bacteria and fungi.

\section{MATERIALS AND METHODS}

\section{Plant material}

Seeds of Pelargonium sidoides DC. were kindly supplied by SEKEM company, Egypt.

\section{Sterilization and incubation conditions}

Seeds were surface sterilized by thoroughly washed under tap water then rinsed with $70 \%$ ethanol for 30 seconds followed by twice washing with sterile water. They were then immersed in 50\% sodium hypochlorite solution for $15 \mathrm{~min}$ after which they were rinsed with sterile water four times and cultured on MS-medium (Murashige and Skoog, 1962) free hormones containing 3\% sucrose and $0.7 \%$ agar. Seeds were transferred in a growth chamber at $26 \pm 1{ }^{\circ} \mathrm{C}$ under light conditions of $16 \mathrm{~h}$ photoperiod. After one-month seedlings were used as the starting plant material.

\section{Callus cultures formation}

\section{Callus culture initiation}

Leaf, root, and shoot tip segments were separated from the produced seedlings and cultured on solidified MS medium with different supplementation: a) $1.0 \mathrm{mg} / 1$ Dichlorophenoxy acetic acid (2,4-D) + $0.2 \mathrm{mg} / 1$ Kinetin (Kin), b) $1.0 \mathrm{mg} / 1$ naphthalene acetic acid (NAA) + $0.2 \mathrm{mg} / \mathrm{l} \mathrm{Kin,} \mathrm{c)} 1.0 \mathrm{mg} / \mathrm{l} \mathrm{NAA}+5.0 \mathrm{mg} / \mathrm{l}$ BA. Cultures were kept in the culture room under a temperature of $26 \pm 1{ }^{\circ} \mathrm{C}$ and light conditions of $16 \mathrm{~h}$ photoperiod. Initiated callus was observed after 4 weeks of cultivation then the callus initiation frequency (\%) was calculated based on the following equation:

Callus initiation frequency $\%=(($ Number of initiated calli)/(Number of inculated explants) $) \times 100$.

\section{Callus production and growth index}

The growth characterization of callus culture and their optimal time of sub-culturing were studied. Therefore, $0.3 \mathrm{~g}$ of $P$. sidoides callus which formed in the previous experiment was transferred to the best combination medium $(1.0 \mathrm{mg} / \mathrm{l} \mathrm{NAA}+$ $0.2 \mathrm{mg} / \mathrm{l} \mathrm{Kin}$ ). Average fresh weight (g) was recorded weekly for six weeks, then growth index was calculated according to the following equation of Dung et al. (1981):

Growth index $=($ Final callus fresh weight - Initial callus fresh weight)/(Initial callus fresh weight).

\section{Extraction method and determination analysis}

\section{Extracts preparation}

Dried powdered samples of in vitro callus cultures derived from leaf, root, and shoot tip explants were extracted using three different solvents. These are water, methanol (85\%) and acetone $(80 \%)$ for $24 \mathrm{hrs}$ at room temperature. The extracts were collected, filtered and evaporated to dryness. Each residue was dissolved in same extract solvent and stored at $4^{\circ} \mathrm{C}$ until further use.

the formula:

The extraction yield percentage was calculated using

$$
\begin{gathered}
\text { Extraction yield }(\%)=((\text { Weight of the extract }) /(\text { Weight of } \\
\text { dried callus })) \times 100 .
\end{gathered}
$$

\section{Determination of total phenolic compounds}

The concentration of phenolic compounds was determined by a spectrophotometric method using the FolinCiocalteu reagent according to Singleton et al. (1999). A calibration curve of gallic acid $(20,40,40,60,80$, and $100 \mu \mathrm{g} / \mathrm{ml})$ was prepared and the absorbance for tests and standard solutions were determined against the reagent blank at $550 \mathrm{~nm}$ with an Ultraviolet (UV)/Visible spectrophotometer. The total phenolic content was expressed as mg of gallic acid equivalent (GAE)/g of dry weight (DW).

\section{Determination of total flavonoids}

The total flavonoids content was measured using a modified colorimetric method of Vabkova and Neugebauerova (2012). The standard curve was prepared using a different concentration of quercetin. The flavonoids content was expressed as mg quercetin equivalents per $g$ of dry weight (DW).

\section{Determination of Total proanthocyanidins}

Total proanthocyanidins were determined by acid $/ n$ butanol method according to the method described by Porter et al. (1986). The absorbance was recorded at $550 \mathrm{~nm}$ using an Ultraviolet (UV)/Visible spectrophotometer. The results were expressed as units at $550 \mathrm{~nm}$ per $\mathrm{mg}$ of extract (A550 nm/mg).

\section{Antimicrobial activity}

The antimicrobial activity of the given $P$. sidiodes extracts was tested against microbial reference cultures, including bacterial strains; two Gram positive (Clostridium perfringenes and Staphylococcus aureus ATCC 6538) and four Gram negative (Shigella flexnerii ATCC 9199, Escherichia coli ATCC 25922, 
Escherichia coli O157 ATCC 700728, Salmonella typhimurium ATCC 14028) as well as one fungal strain (Candida albicans ATCC 2091). The antimicrobial activates were evaluated using agar well diffusion test (Sgouras et al., 2004). Hundred $\mu$ l of cell culture suspension matching with $0.5 \mathrm{McF}$ arland of target strains were spread onto the plates. For the investigation of the antimicrobial activity, $100 \mu \mathrm{l}$ of extracts were added into wells of agar plates directly, oxytetracycline disc (Oxoid) (Oxytetracycline $30 \mu \mathrm{g}$ / disc) as control positive for bacterial stains and Fluconazole (10 $\mu \mathrm{g} / \mathrm{disc})$ as control positive for tested mycotic strain. Plates were left for $1 \mathrm{~h}$ at $25^{\circ} \mathrm{C}$ to allow a period of pre-incubation diffusion in order to minimize the effects of variation in time between the applications of different solutions. The plates were re-incubated at 37 and $30^{\circ} \mathrm{C}$ for bacterial and mycotic strains respectively for $24 \mathrm{~h}$. After incubation, plates were observed for antimicrobial activities by determining the diameters of the zones of inhibition for each strain. For an accurate analysis, tests were run in triplicate for each strain to avoid any error and the means \pm SD were tabulated in the given tables.

\section{Statistical analysis}

The experiments were carried out in triplicate and the results were expressed as means \pm standard errors. Statistical analysis of variance was performed by ANOVA and significant differences (LSD) at $\mathrm{P}$ value $\leq 0.05$ between the means were determined by Duncan's Multiple Range Test.

\section{RESULTS AND DISCUSSION}

\section{Sterilization and incubation conditions}

Disinfection of seeds and subsequently germination is crucial to obtain success explants under the establishment stage of callus cultures. Sterilization with $50 \%$ sodium hypochlorite for $15 \mathrm{~min}$ resulted in highest percentage of contaminated free seedling. Unfortunately, low seed germination percentage (about $30 \%$ of seeds) succeeded to germinate under these sterilization conditions (Figure 1). Seedlings were used as a source of explants in the current study.

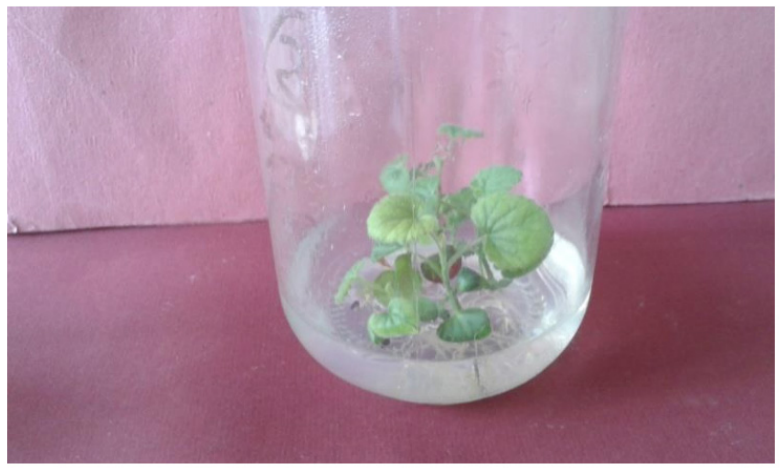

Fig. 1: Seedlings of $P$. sidoides grown on MS-medium after four weeks of cultivation.

\section{Callus culture formation}

This experiment aims to find any combination of growth regulator which give the highest productivity of callus cultures through two steps protocol including callus initiation and callus production.

\section{Callus initiation}

Leaf, root, and shoot tip explants derived from 30 days old seedling were transferred to MS solid media containing different growth regulators. After one month the callus initiation frequency $(\%)$ on the three different combinations was calculated and shown in Figure 2. Data reveals that callus initiation frequency ( $\%$ ) of root and shoot tip was the same in all different combinations. These values were $100 \%$ at the $\mathrm{a}$ and $\mathrm{b}$ combinations and the lowest in the combination $(70 \%)$. While leaf explant showed minimum callus initiation frequency $(\%)$ on all different combinations $(72 \%$, $85 \%$, and $33 \%$ ) on a, b, and c combinations respectively.

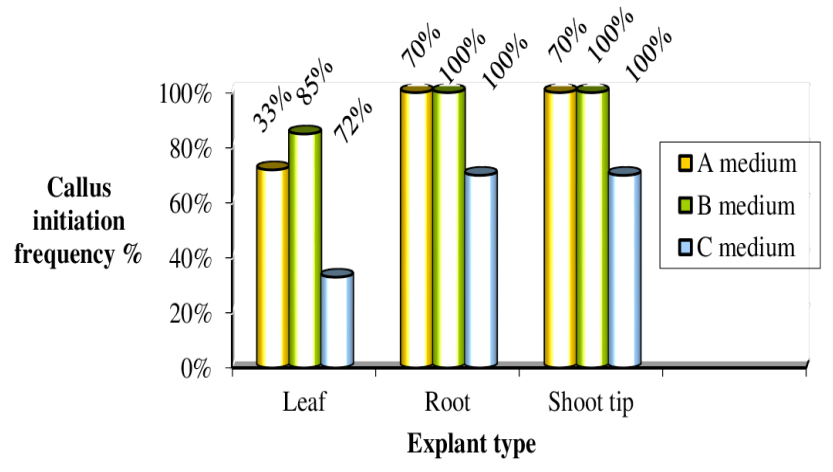

Fig. 2: Callus initiation frequency (\%) of leaf, root, and shoot tip explants cultivated on different growth regulators combinations: A $(1.0 \mathrm{mg} / 1$ 2,4-D + $0.2 \mathrm{mg} / 1 \mathrm{Kin}), \mathrm{B}(1.0 \mathrm{mg} / 1 \mathrm{NAA}+0.2 \mathrm{mg} / 1 \mathrm{Kin})$ and $\mathrm{C}(1.0 \mathrm{mg} / 1 \mathrm{NAA}+5.0$ $\mathrm{mg} / 1 \mathrm{BA})$.

To investigate the effect of these different combinations for getting healthy calli, the brown deposits formation was followed in all different combinations. We observed that, the two combinations (1.0 mg/1 2,4-D and $0.2 \mathrm{mg} / \mathrm{l} \mathrm{Kin} \mathrm{and} 1.0 \mathrm{mg} / \mathrm{l} \mathrm{NAA}$ $+5.0 \mathrm{mg} / \mathrm{l} \mathrm{BA}$ ) obtained calli with brown color abounding, while the NAA and Kin combination was the best to get friable calli with little brown deposits as shown in Figure 3.

The present combination (NAA and Kin) was first used by Moyo et al. (2012) to initiate calli from petioles explant of $P$. sidoides and obtained calli with crumbly consistence. Our results agree with Duchow et al. (2014) in that the 2,4-D and Kin combination obtained calli with many brown deposits and does not agree with them in that the combination of NAA and BAP resulted in rapid growth of calli with little brown color abounding. In this respect, successfully achieved of callus culture induction from leaves, stems, and seeds of $P$. sidoides using auxin alone like 2,4-D and indole butyric acid (IBA) was reported by Lewu et al. (2007). Other pelargonium species induced calli with optimal growth by using balancing amount of auxins and cytokinins (Brown and Charlwood, 1986).

Leaves formation were observed with callus induction by using single shoot tip explant (Figure 4A) on different combinations. These shoots were taken after calli isolation and transferred to the same media to examine shoot tip development. Obtained results after one month showed that no development occurred in these shoots (Figure 4B). Duchow et al. (2014) mentioned that there are little researches about micro-propagation of P. sidoides. On the opposite Moyo et al. (2012) succeed in shoot induction and multiplication with rooting formation by 
using different types and concentrations of cytokinins alone. In the present study, $1.0 \mathrm{mg} / \mathrm{l}$ of BA was also used to observe shoot tip development. After one month the new leaves were formed on this medium, but no root formation was observed (Figure 5).
These shoots were sub-cultured on the same medium $(1.0 \mathrm{mg} / \mathrm{l}$ BA) for three months further to obtain new shoots. In this further experiment, we observed that shoots failed in multiplication and new shoots formation resulted after three months.
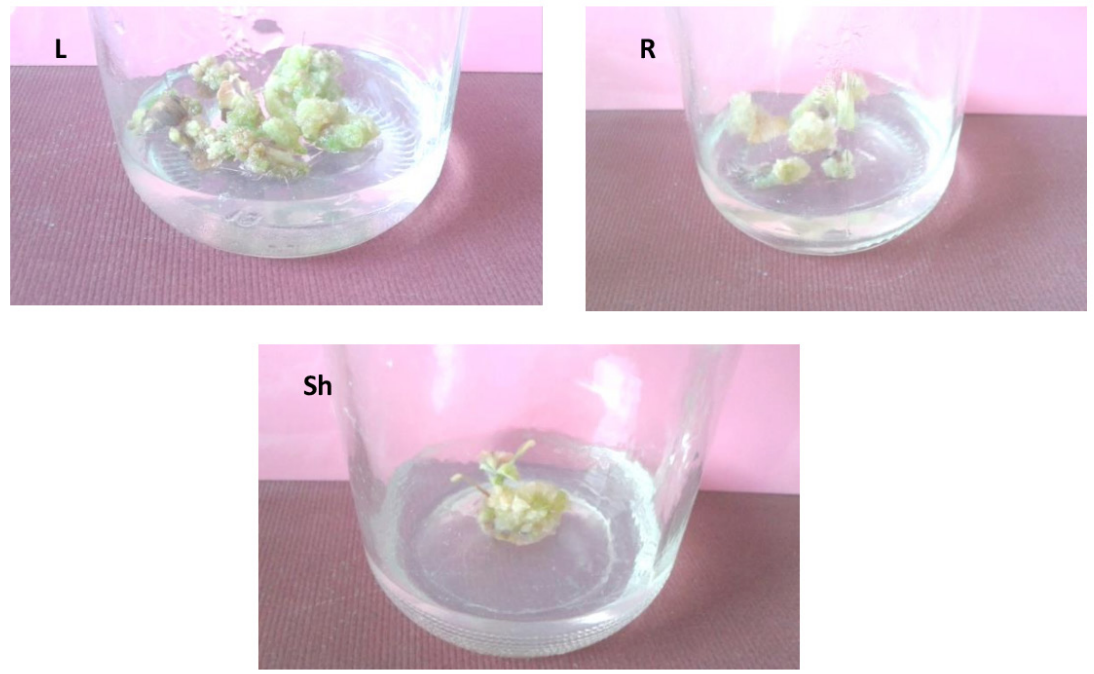

Fig. 3: Callus initiation from leaf (L), root (R) and shoot tip (Sh) explants on the best medium (1.0 mg/1 NAA $+0.2 \mathrm{mg} / 1 \mathrm{Kin})$ after one month.
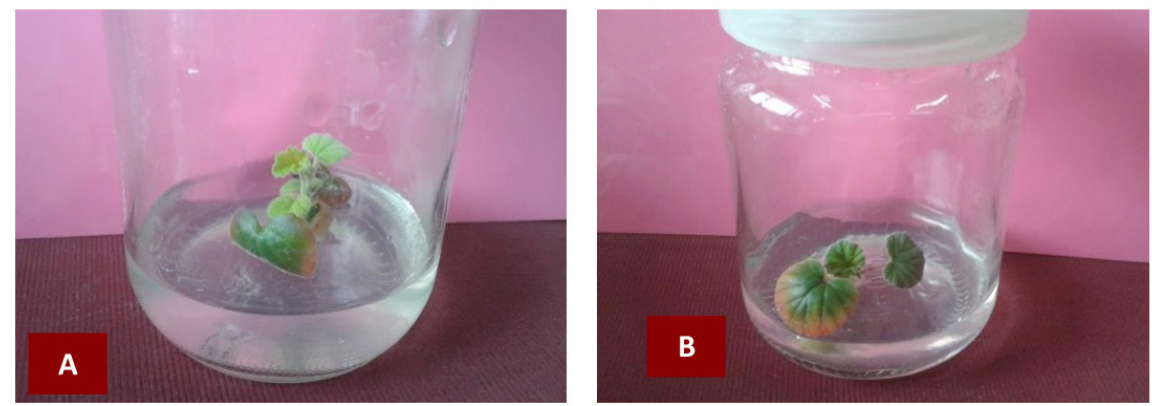

Fig. 4: Shoot formation with callus induction using shoot tip explant (A) and no development after one month (B) on the same medium (1.0 mg/1 NAA $+0.2 \mathrm{mg} / 1 \mathrm{Kin})$.

\section{Callus production and growth index}

As previously mentioned the combination of NAA and Kin was the best for obtaining healthy callus cultures, so it was applied for getting the highest productivity of callus cultures. Initiated calli derived from leaf, root, and shoot tip explants were examined for callus production depending on their fresh weights and growth index as shown in Table 1.

Callus fresh weights and growth index which obtained for six weeks showed that the maximum increasing value of fresh weight was observed slightly at the fifth week in all explants then rapidly decreased at the sixth week.

Concerning the influence of explant type on the productivity of calli, the maximum values of fresh weight and growth index were recorded with root explant (4.01 g and 12.37) followed by leaf explant (3.98 $\mathrm{g}$ and 12.27$)$ respectively. On the other hand, the calli from shoot tip explant recorded the minimum values (2.72 $\mathrm{g}$ and 8.07$)$ in the fifth week respectively. Obtained calli was sub-cultured on the best combination (NAA and Kin), after three months rapid mass production of calli was obtained (Figure 5) then it used in phytochemical analysis and antimicrobial activity tests.

\section{Extraction method and determination analysis}

Extraction process of the bioactive components from medicinal plants is a substantial step for retrieval of these components and obtained it in a pure form. Using different solvents for extraction and determination of phenolic and flavonoids compounds were studied and suggested in various researches (Tatiya et al., 2011; Addai et al., 2013). In the current experiment, we discuss the effect of two variables (explant type and extraction solvents) on the yield percentage and total bioactive components content (phenolics, flavonoids, and proanthocyanidins).

\section{Extraction yield percent evaluation}

Estimation of percentage yield extracts (w/w) of $P$. sidoides calli obtained with different solvents is displayed in Table 2. Results 
show that the extraction calli of shoot tip explant with aqueous acetone solvent gave maximum extraction yield percent $(77.8 \%)$ followed by water solvent extraction of the same calli explant (44.4\%). Generally, calli from shoot tip explant extracted by various solvents (aqueous methanol, aqueous acetone, and water) were the highest extraction yield percent from calli of leaf and root explants extracted with the same solvent. Contrary the extraction with aqueous methanol solvent gave the minimum extraction yield percent of different calli explants compared to their counterpart in other extracts (water and aqueous acetone), where minimum extraction yield percent was recorded with calli from root explant extracted by aqueous methanol solvent $(12.8 \%)$. Our results are in contrast with Chatha et al. (2006) who achieved maximum extraction yield by using aqueous methanol from rice bran. Similarly, Vaghasiya and Chanda (2007) found that the extraction yield of fourteen Indian medicinal plants was more in methanol than acetone. These differences may be attributed to the diversity of the existing components in different plant materials. In the present work, the differences of extraction yield possibly could be attributed to the variations of solvents or quantity of components in different calli explants.

Table 1: Fresh weights and growth indexes of callus cultures from leaf, root, and shoot tip explants of $P$. sidoides for six weeks.

\begin{tabular}{|c|c|c|c|}
\hline $\begin{array}{l}\text { Callus from } \\
\text { different explants }\end{array}$ & $\begin{array}{c}\text { Incubation } \\
\text { period (week) }\end{array}$ & $\begin{array}{c}\text { Callus fresh } \\
\text { weight (g) }\end{array}$ & $\begin{array}{l}\text { Callus growth } \\
\text { index }\end{array}$ \\
\hline \multirow{6}{*}{ Leaf } & 1 & $0.59 \pm 0.02$ & 0.97 \\
\hline & 2 & $0.98 \pm 0.07$ & 2.27 \\
\hline & 3 & $1.76 \pm 0.02$ & 4.87 \\
\hline & 4 & $2.05 \pm 0.10$ & 5.83 \\
\hline & 5 & $3.98 \pm 0.20$ & 12.27 \\
\hline & 6 & $1.77 \pm 0.20$ & 4.90 \\
\hline \multirow{6}{*}{ Root } & 1 & $0.80 \pm 0.01$ & 1.67 \\
\hline & 2 & $0.82 \pm 0.04$ & 1.73 \\
\hline & 3 & $1.20 \pm 0.05$ & 3.00 \\
\hline & 4 & $1.99 \pm 0.10$ & 5.63 \\
\hline & 5 & $4.01 \pm 0.80$ & 12.37 \\
\hline & 6 & $2.01 \pm 0.1$ & 5.70 \\
\hline \multirow{6}{*}{ Shoot tip } & 1 & $0.51 \pm 0.06$ & 0.70 \\
\hline & 2 & $0.79 \pm 0.03$ & 1.63 \\
\hline & 3 & $1.21 \pm 0.10$ & 3.03 \\
\hline & 4 & $1.54 \pm 0.10$ & 4.13 \\
\hline & 5 & $2.72 \pm 0.30$ & 8.07 \\
\hline & 6 & $1.38 \pm 0.10$ & 3.60 \\
\hline
\end{tabular}

\section{Determination of total phenolic compounds}

Determination of total phenolic compounds under the influence of explant type and extraction solvent have been clear in Figure 6. Data indicate that callus from root explant extracted with aqueous acetone exhibited the manifest increase in total phenolic compounds value $(12.34 \mathrm{mg} / \mathrm{g} \mathrm{DW})$ compared with the others, followed by callus from shoot tip extracted with aqueous acetone also $(4.78 \mathrm{mg} / \mathrm{g} \mathrm{DW})$. This observation quite agrees with Tatiya et al. (2011) who mentioned that the maximum phenolic content in Bridelia retusa bark extract $(14 \% \mathrm{~W} / \mathrm{W})$ was detected using aqueous acetone compared with other extracts (water, aqueous ethanol, and aqueous methanol).

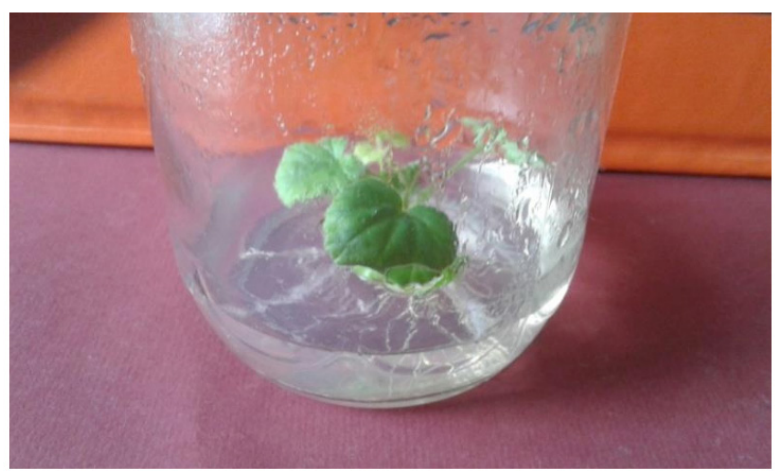

Fig. 5: New leaves formation after one month on the medium containing 1.0 $\mathrm{mg} / 1 \mathrm{BA}$.

Table 2: Extraction yield percent (W/W) of $P$. sidoides calli derived from leaf, root and shoot tip explants extracted with different solvents.

\begin{tabular}{lcc}
\hline Solvents & $\begin{array}{c}\text { Callus of different } \\
\text { explants }\end{array}$ & $\begin{array}{c}\text { Extraction yield } \\
(\mathbf{\%}(\mathbf{w} / \mathbf{w}) \mathbf{)}\end{array}$ \\
\hline \multirow{2}{*}{ Methanol 85\% } & Leaf & 15.2 \\
& Root & 12.8 \\
Acetone $80 \%$ & Shoot tip & 27.8 \\
& Leaf & 21.0 \\
& Root & 20.0 \\
Water & Shoot tip & 77.8 \\
& Leaf & 20.0 \\
& Root & 32.9 \\
\hline
\end{tabular}

In contrast, Addai et al. (2013) recorded high total phenolic content $(7.05 \mathrm{mg} / \mathrm{g} \mathrm{DW})$ from two papaya cultivars in aqueous methanol extract compared with water, aqueous ethanol, and aqueous acetone. This difference probably due to the variation of existent phenolic compounds in various plant materials, as phenolic compounds varied from simple (phenolic acids, anthocyanins) to highly polymerized substances (e.g., tannins), also phenolic compounds may be linked with other substances like carbohydrates and proteins. So, there is no common solvent appropriate for phenolic extraction because it depends on the type of plant material.

In the present study, using of aqueous methanol for phenolic extraction from different callus explants showed minimum phenolic content values, while the minimum value of phenolic was observed with calli from root explant extracted with aqueous methanol $(0.41 \mathrm{mg} / \mathrm{g} \mathrm{DW})$. This finding is contradictory with several studies utilized the aqueous methanol for phenolic compounds extraction (Bonoli et al., 2004; Chatha et al., 2006; Sultana et al., 2009; Shabbir et al., 2011). Several studies revealed that phenolic compounds content differed with solvents polarities. For example, pure methanol was used for the extraction of tea polyphenols (Yao et al., 2006) and 50\% acetone for extraction of wheat total phenolics (Zhou and Yu, 2004) which were found to be more effective than water. 

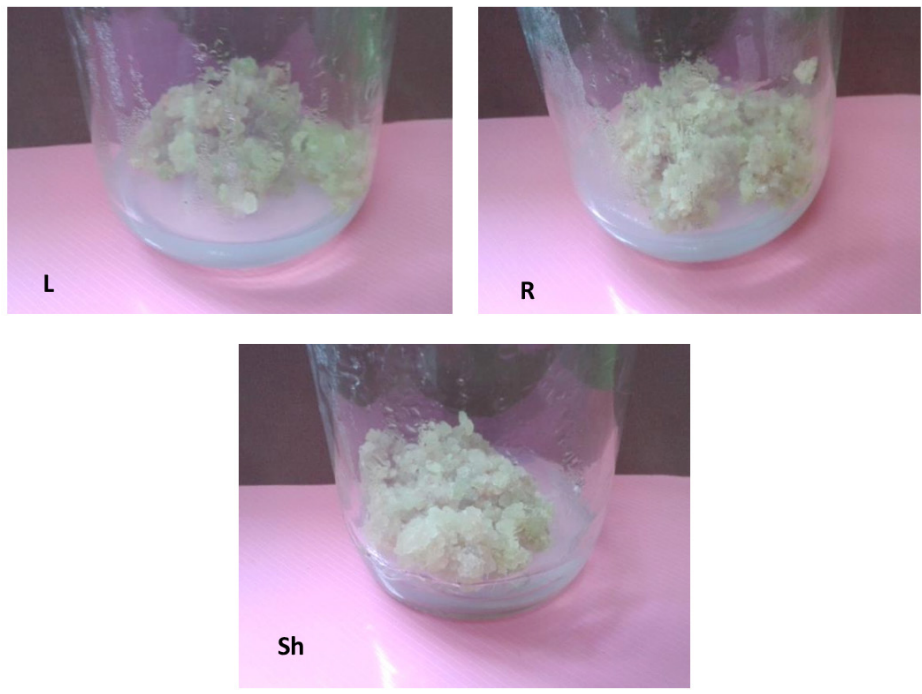

Fig. 6: Callus production from leaf (L), Root (R) and shoot tip (Sh) explants sub-cultured on $1.0 \mathrm{mg} / 1 \mathrm{NAA}+0.2 \mathrm{mg} / 1 \mathrm{Kin}$ combination after three months.

Statistical analysis shows that there are significant differences in total phenolic contents between different extracts whether it is due to the explant type which consists of calli or type of the solvent. This means that these two aforementioned variations have a clear impact on phenolic compounds accumulation and it must be taken into account when phenolic compounds were extracted.

\section{Determination of total flavonoids}

Determination of total flavonoids in calli extracts from different explants and diverse solvents was determined and showed in Figure 7. Data elucidate that, total flavonoids concentrations ranged from 1.69 to $20.82 \mathrm{mg} / \mathrm{g} \mathrm{DW}$ and going in the same trend of total phenolic compounds determination. The maximum total flavonoids concentration was observed with calli from root explant extracted with aqueous acetone $(20.82 \mathrm{mg} / \mathrm{g} \mathrm{DW})$, followed by calli from shoot tip explant extracted with aqueous acetone $(10.72$ $\mathrm{mg} / \mathrm{g}$ DW). This observation agrees with Stankovic et al. (2012) who mentioned that the acetone extract of Teucrium polium L. leaves showed higher amounts of flavonoids content than the other examined extracts (water, methanol, ethyl acetate and petroleum ether). Also, Adaramola and Onigbinde (2016) found that the highest flavonoids of clove bud were obtained for $80 \%$ acetone followed by the $80 \%$ methanol and the least were obtained for the water extract.

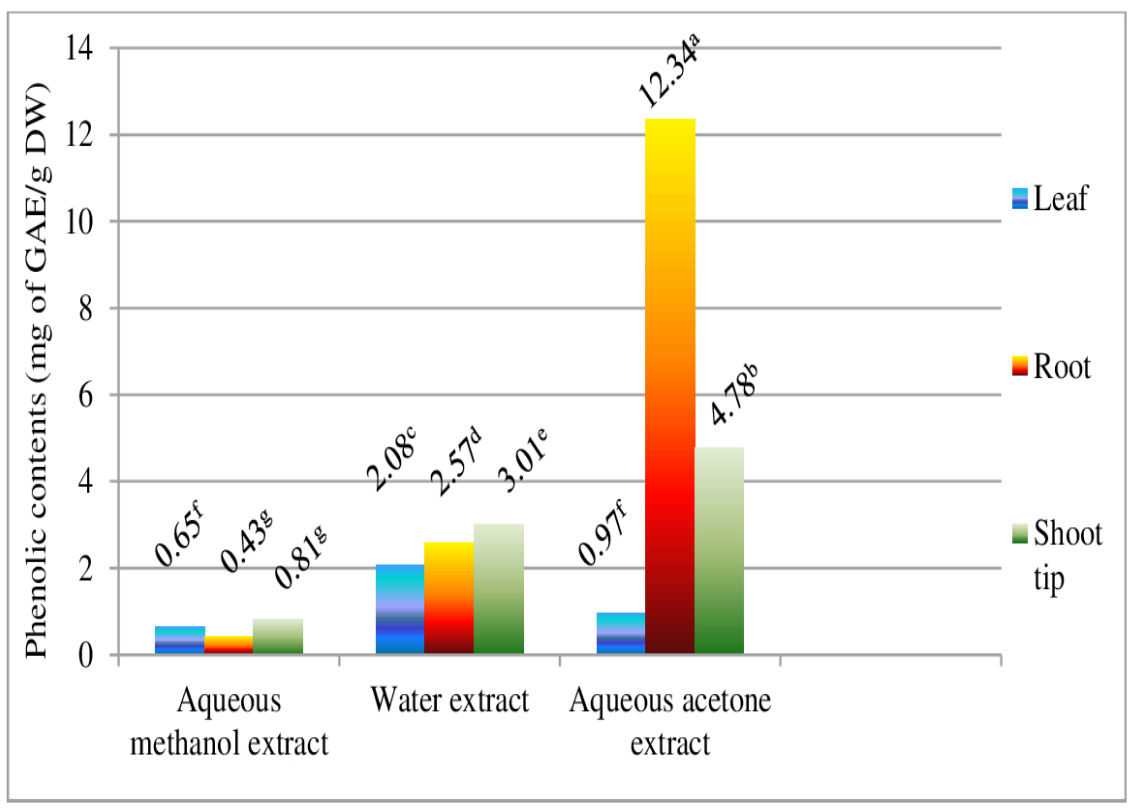

Fig. 7: Total phenolic compounds (mg of GAE/g DW) of P. sidiodes calli from different explants extracted with aqueous methanol, water, and aqueous acetone. Small letter express LSD significant differences $\left(\mathrm{LSD}_{0.050}\right.$ value $\left.=0.3473\right)$. 
In the opposite manner, Mohammadi et al. (2016) detected highest total flavonoids content of Anabasis setifera and Salsola tomentosa plants by using methanol as the solvent for extraction compared with acetone solvent. Also, Butsat and Siriamornpun (2016) found that the $80 \%$ methanol extract of Amomum Chinese leaves gave the greatest yield of total flavonoids compared with other extracts (water and aqueous acetone). As well as the differences of phenolic compounds varied depending on the type of plant materials, the same explanation is stood for flavonoids.

Total flavonoids contents of calli from different explants extracted with water were higher than aqueous methanol extracts for calli from all explants. Minimum flavonoids content (1.69 $\mathrm{mg} / \mathrm{g}$ DW) was observed with calli from leaf explant extract by aqueous acetone.

Statistical analysis shows that there are significant differences in total flavonoids contents between calli from different explants in aqueous acetone extract, in contrast with aqueous methanol extracts there are no significant differences between different explants, but in water extract, there are no differences between root and shoot tip explants. These results demonstrated that the solvent type is more important as an effective factor for total flavonoids content.

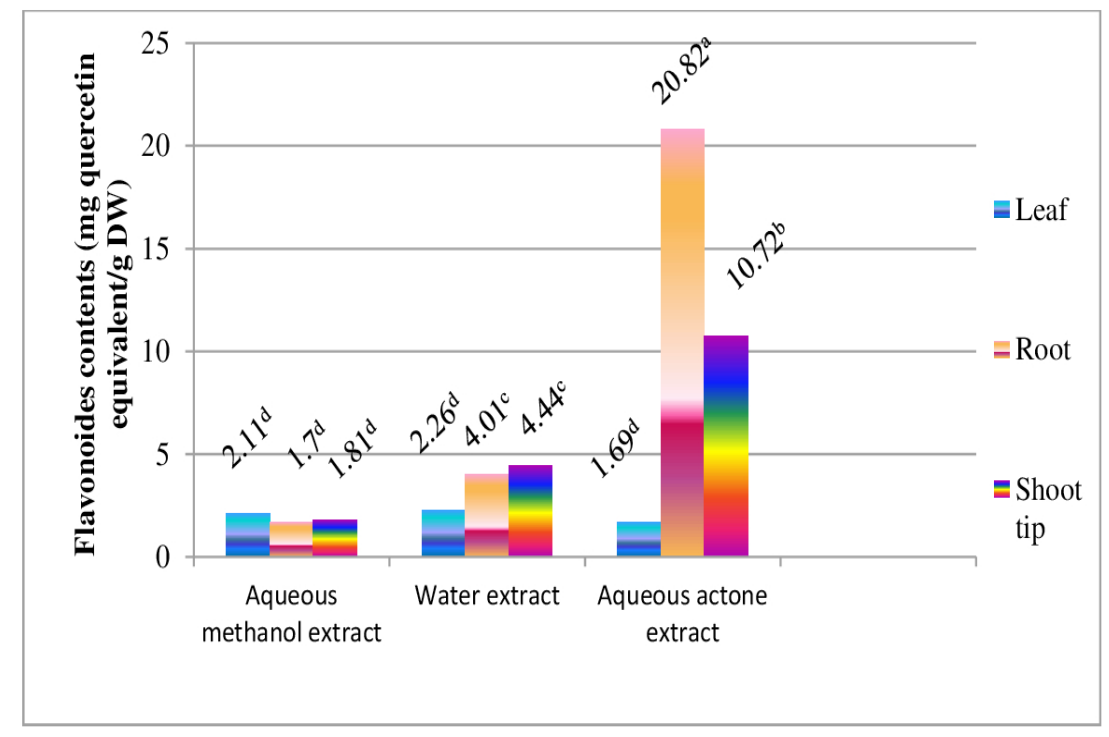

Fig. 8: Total flavonoid contents (mg of quercetin equivalent/g DW) of aqueous methanol, water and aqueous acetone of $P$. sidiodes calli from different explants. Small letter express LSD significant differences $\left(\mathrm{LSD}_{0.050}\right.$ value $\left.=1.276\right)$.

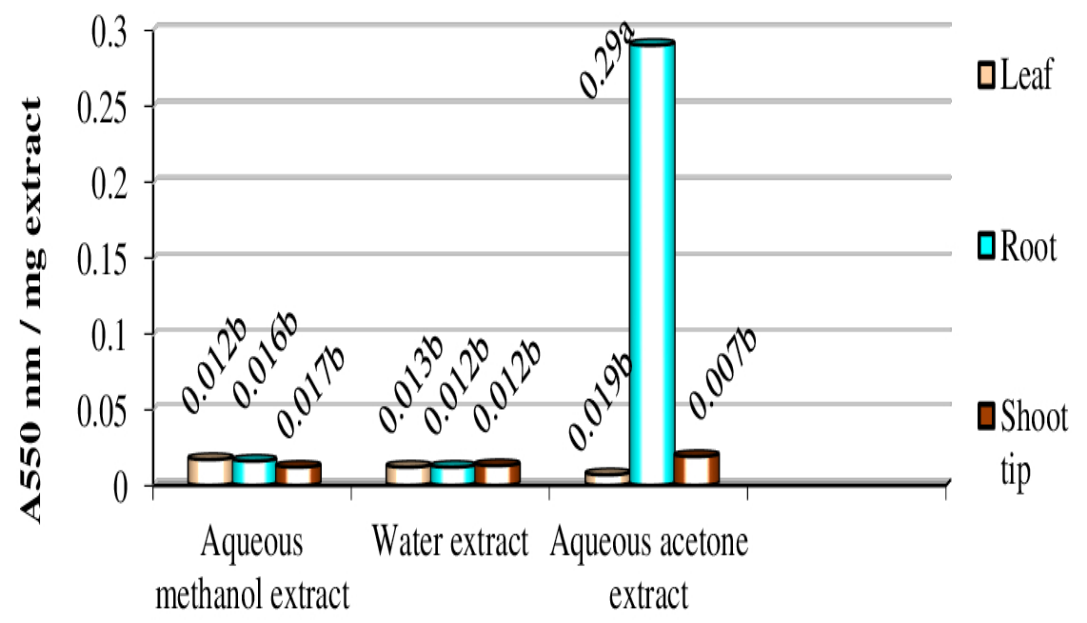

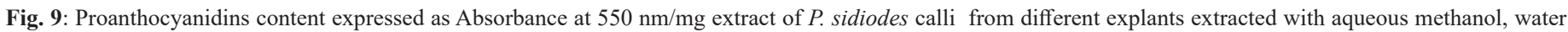
and aqueous acetone. Small letters express LSD significant differences $\left(\mathrm{LSD}_{0.050}\right.$ value $\left.=0.0543\right)$. 


\section{Determination of total proanthocyanidins}

Proanthocyanidins are condensed tannin compounds found in some food or medicinal plants, it is a powerful antioxidant agent, so it is a health-promoting factor, some literature suggested that it has antimicrobial properties (Chung et al., 1993; Katiyar and Mukhtar, 1997; Amarowicz et al., 2000b). A colorimetric method of $n$-butanol/ $\mathrm{HCl}$ hydrolysis is performed to detect these components. Data in Figure 8 indicate that the $A_{550} \mathrm{~nm} / \mathrm{mg}$ extract recorded the maximum value for only callus from root extracted with aqueous acetone (0.290). Other extracts noted low values (from 0.007 to 0.019 ) and there are no significant differences between them.

Some investigations subjected to proanthocyanidins evaluation in several plants such as legume seeds (WilskaJeszka and Stasiak, 1984), the high content of these compounds were detected in faba bean (Amarowicz et al., 2000a). Also, the ethanolic and acetonic extracts of hazelnuts (Alasalvar et al., 2006) and in almonds extract as reported by Amarowicz et al. (2005). The existence of principal plant metabolite predominated in root extract of $P$. sidoides. Accordingly, high molecular weight proanthocyanidins compound showed the same trend (Kolodziej and Kayser, 1998). Moreover, the most researches on $P$. sidiodes that were performed on root extract in order to the curative properties of different compounds occurred in such plants (Kolodziej et al., 2003; Mativandlela et al., 2007).

\section{Antimicrobial analysis}

Crude methanol and acetone extracts from calli of all explants were tested against two Gram-positive and four Gramnegative bacteria strains as well as they were tested against one fungal strain. The inhibition zone diameters $(\mathrm{mm})$ were recorded to reflect the activity of their extracts.

\section{Antimicrobial activity of methanol extracts}

Data in Table 3 clarify that all methanol extracts showed an inhibitory effect against all tested strains. Leaf culture of $P$. sidiodes extracted with methanol recorded maximum inhibition zone diameters against $E$. coli ATCC $25922(20 \mathrm{~mm})$, this value is higher than root and shoot tip cultures extracted with methanol against the same strain. The inhibition zone diameters of the leaf extract against $S$. aureus ATCC 6538 and Shigella flexneri ATCC $9199(19 \mathrm{~mm})$ were the same of those in root culture extract and higher than shoot tip culture extract. While leaf extract showed minimum zone diameters against Salmonella typhimurium ATCC 14028 (11.3 mm) and Candida albicans ATCC 2091 (12 mm), these values were lower than inhibition zone diameters resulted from the root and shoot tip cultures.

Table 3: Inhibition zone diameters of methanolic $P$. sidiodes calli crude extracts produced from leaf, root, and shoot tip explants against some microbial species.

\begin{tabular}{|c|c|c|c|c|}
\hline \multirow{2}{*}{ Microbial culture } & \multicolumn{4}{|c|}{ Inhibition zone diameter $($ Mean \pm SD) $(\mathrm{mm})$} \\
\hline & Callus from leaf & Callus from root & Callus from shoot tip & Oxytetracycline or Fluconazole \\
\hline Clostridium perf. ATCC & $17.0 \pm 2.08$ & $10.0 \pm 0.58$ & $8.0 \pm 0.00$ & $30.0 \pm 1.00$ \\
\hline S. aureus ATCC 6538 & $19.0 \pm 1.00$ & $19.0 \pm 1.15$ & $13.0 \pm 1.52$ & $29.7 \pm 1.20$ \\
\hline Shigella flexneri ATCC 9199 & $19.0 \pm 1.73$ & $19.0 \pm 1.15$ & $13.0 \pm 1.53$ & $30.0 \pm 1.15$ \\
\hline E. coli ATCC 25922 & $20.0 \pm 1.73$ & $12.0 \pm 0.58$ & $14.0 \pm 0.58$ & $24.0 \pm 1.00$ \\
\hline E. coli $\mathrm{O} 157$ ATCC 700728 & $16.0 \pm 0.58$ & $24.0 \pm 1.15$ & $24.0 \pm 1.00$ & $36.0 \pm 1.15$ \\
\hline Salmonella typhimurium ATCC 14028 & $11.3 \pm 1.20$ & $15.0 \pm 1.52$ & $26.0 \pm 1.52$ & $20.0 \pm 0.58$ \\
\hline Candida albicans ATCC 2091 & $12.0 \pm 1.00$ & $15.0 \pm 1.53$ & $15.0 \pm 1.53$ & $30.0 \pm 1.73$ \\
\hline
\end{tabular}

Inhibition zone diameters of root culture extracted with methanol ranged from $10 \mathrm{~mm}$ against Clostridium perfringens ATCC and $24 \mathrm{~mm}$ against E. coli O157 ATCC 700728 and showed moderate activity against other strains.

The methanol extract of shoot tip culture recorded maximum inhibition $(26 \mathrm{~mm})$ against Salmonella typhimurium ATCC 14028 and against E. coli O157 ATCC 700728 (24 $\mathrm{mm})$, while it recorded minimum inhibition $(8 \mathrm{~mm})$ against Clostridium perfringens ATCC and showed moderate activity against other tested microbial strains. Inhibition zone diameters of Oxytetracycline or Fluconazole were the highest against all tested microbial strains except against Salmonella typhimurium ATCC $14028(20 \mathrm{~mm})$ whereas shoot tip extract recorded higher zone diameter $(26 \mathrm{~mm})$.

\section{Antimicrobial activity of acetone extract}

Data in Table 4 elucidate that all crude acetone extracts have activity against all microbial strains; this activity is different depending on the type of microbes either sensitive or resistant. It is noted that some microbes are sensitive to one extract and resistant in the others like Shigella flexneri ATCC 9199 as it was more sensitive to shoot tip extract as gave inhibition zone diameter $35 \mathrm{~mm}$ while it was less sensitive to leaf extract (inhibition zone diameter $16 \mathrm{~mm}$ ) whereas root extract had moderate activity between them (inhibition zone diameter $22 \mathrm{~mm}$ ), also Salmonella typhimurium ATCC 14028 going the same line while maximum activity recorded with shoot tip extract. On the contrary we found that the maximum activity of leaf extract $(32 \mathrm{~mm})$ recorded against E. coli ATCC 25922, this was asymptotic of the activity of root and shoot tip extracts, furthermore leaf extract had distinguished activity against E. coli 0157 ATCC 700728 (inhibition zone diameter was $30 \mathrm{~mm}$ ) this value is less than the activity of root and shoot tip extracts.

Inhibition zone diameter of root extract ranged from $11.3 \mathrm{~mm}$ against Candida albicans ATCC 2091 to $30 \mathrm{~mm}$ against E. coli ATCC 25922 and showed middling activity against other microbes. While shoot tip extract had maximum inhibition zone diameters (35 mm) against Shigella flexneri ATCC 9199 and Clostridium perf. ATCC and showed minimum inhibition zone diameter (18 mm) against E. coli O157 ATCC 700728 and has made good activity against other microbes.

Oxytetracycline or Fluconazole achieved the highest 
activity from three extracts against some microbes such $S$. aureus ATCC 6538, E. coli O157 ATCC 700728 and Candida albicans ATCC 2091, but unlike with other microbes such as Clostridium perf. ATCC, Shigella flexneri ATCC 9199 and Salmonella typhimurium ATCC 14028 where higher inhibition zone diameters recorded with shoot tip extract $(35 \mathrm{~mm}, 35 \mathrm{~mm}$ and $30 \mathrm{~mm}$ ) respectively. Also along the same line, E. coli ATCC 25922 recorded higher activity with leaf extract (inhibition zone diameter $32 \mathrm{~mm}$ )

Table 4: Inhibition zone diameters of acetonic P. sidiodes calli crude extract produced from leaf, root, and shoot tip explants against some microbial species.

\begin{tabular}{lcccc}
\hline \multirow{2}{*}{ Microbial culture } & \multicolumn{3}{c}{ Inhibition zone diameter (Mean \pm SD) $(\mathbf{m m})$} \\
\cline { 2 - 5 } & Callus from leaf & Callus from root & Callus from shoot tip & Oxytetracycline or Fluconazole \\
\hline Clostridium perf. ATCC & $20.0 \pm 1.15$ & $22.0 \pm 2.31$ & $35.0 \pm 0.58$ & $30.0 \pm 1.00$ \\
S. aureus ATCC 6538 & $22.0 \pm 2.31$ & $20.0 \pm 1.15$ & $20.0 \pm 1.15$ & $29.7 \pm 1.20$ \\
Shigella flexneri ATCC 9199 & $16.0 \pm 1.00$ & $22.0 \pm 1.53$ & $35.3 \pm 0.88$ & $30.0 \pm 1.15$ \\
E. coli ATCC 25922 & $32.0 \pm 2.00$ & $30.0 \pm 2.00$ & $25.0 \pm 1.15$ & $24.0 \pm 1.00$ \\
E. coli O157 ATCC 700728 & $30.0 \pm 1.00$ & $18.0 \pm 1.00$ & $18.0 \pm 0.00$ & $36.0 \pm 1.15$ \\
Salmonella typhimurium ATCC 14028 & $16.0 \pm 1.52$ & $20.7 \pm 0.88$ & $30.0 \pm 2.31$ & $20.0 \pm 0.58$ \\
Candida albicans ATCC 2091 & $12.0 \pm 0.57$ & $11.3 \pm 1.33$ & $25.0 \pm 1.53$ & $30.0 \pm 1.73$ \\
\hline
\end{tabular}

In the previous studies of Collins and Franzblau (1997), they discovered that the crude extract of $P$. sidoides root showed proclaimed growth inhibition of Mycobacterium tuberculosis by 96\%. Furthermore, Mativandela et al. (2007) found that butanol root extract of $P$. sidoides has inhibitory properties against Mycobacterium tuberculosis and Mycobacterium smegmatis. Epigallocatechin and scopoletin showed restrained action against M. smegmatis with minimum inhibitory concentration (MIC) of $7.8 \mathrm{mg} / \mathrm{ml}$. Catechin and umckalin showed MIC values of 31.25 and $62.5 \mathrm{mg} / \mathrm{ml}$ respectively. Kolodziej et al. (2003) proved that $P$. sidoides extracts may have own antibacterial activity as supposed in conventional uses and they also observed antibacterial activity against multi-resistant Staphylococcus aureus strains. Lewu et al. (2006) tested acetone and methanol extracts of $P$. sidoides from shoot and root as antimicrobial activity against 10 bacterial and 5 fungal strains and reported that two extracts showed considerable activity against all Gram-positive bacteria and two strains of Gramnegative bacteria, as well as showed perceivable activity against all fungal strains with inhibition percent ranged from $52.5 \%$ to $82.5 \%$. These results have been interpreted that $P$. sidiodes extract has antimicrobial activity with possibility wide range effect. This supports the idea of using of $P$. sidiodes for various infections treatment.

\section{CONCLUSION}

Plant cell cultures can certainly contribute to the development of various industries, especially the pharmaceutical industry. For this reason, this study was conducted to clarify the best growth regulator combination which gives the best results for callus initiation and callus production from different explants. The recovery of secondary metabolites relies on the extraction solvent. So, in this work, we used three different solvents (aqueous methanol, water, and aqueous acetone), and results clearly showed that aqueous acetone was the best solvent for phenolic, flavonoids and proanthocyanidins contents. Also, the results show that calli from root explant was the best than the others. This is because the extract of the roots of Pelargonium sidoides DC. has a distinctive therapeutic property and previously used in traditional medicine. Also, this work confirmed that both aqueous methanol and aqueous acetone extracts have a clear impact as an antimicrobial agent with wide range effect. In conclusion, the application of bioactive compounds obtained from different parts of $P$. sidoides could be applied in both pharmaceuticals and food industries.

\section{ACKNOWLEDGMENT}

This research is quite compatible with the research plan of National Research Centre. The authors are greatly indebted to the NRC for the generous financing support that enables us to achieve these results.

\section{REFERENCES}

Adaramola B, Onigbinde A. Effect of extraction solvent on the phenolic content, flavonoid content and antioxidant capacity of clove bud. IOSR J Pharm Biol Sci. 2016; 11:33-38.

Addai ZR, Abdullah A, Abd-Mutalib SA. Effect of extraction solvents on the phenolic content and antioxidant properties of two papaya cultivars. J Med Plants Res. 2013; 7:3354-3359.

Alasalvar C, Karamać M, Amarowicz R, Shahidi F. Antioxidant and antiradical activities in extracts of hazelnut kernel (Corylus avellana L.) and hazelnut green leafy cover. J Agric Food Chem. 2006; 54:4826-4832.

Amarowicz R, Naczk M, Zadernowski R, Shahidi F. Antioxidant activity of condensed tannins of beach pea, canola hulls, evening primrose, and faba bean. J Food Lipids. 2000a; 7:195-205.

Amarowicz R, Pegg RB, Bautista DA. Antibacterial activity of green tea polyphenols against Escherichia coli K12. Nahrung. 2000b; 44:60-62.

Amarowicz R, Troszyńska A, Shahidi F. Antioxidant activity of almond seed extract and its fractions. J Food Lipids. 2005; 12:344-358.

Bonoli M, Verardo V, Marconi E, Caboni MF. Antioxidant phenols in barley (Hordeum vulgare L.) flour: comparative spectrophotometric study among extraction methods of free and bound phenolic acids. J Agric Food Chem. 2004; 52:5195-5200.

Brown JT, Charlwood BV. The control of callus formation and differentiation in scented pelargoniums. J Plant Physiol. 1986; 123:204-217.

Butsat S, Siriamornpun S. Effect of solvent types and extraction times on phenolic and flavonoid contents and antioxidant activity in leaf extracts of Amomum chinense C. Int Food Res J. 2016; 23:180-187.

Chatha SAS, Anwar F, Manzoor M, Bajwa JR. Evaluation of the antioxidant activity of rice bran extracts using different antioxidant assays. Grasas Aceites Sevilla. 2006; 57:328-335.

Chung KT, Stevens SE, Lin WF. Growth inhibition of selected food-borne bacteria by tannic acid, propyl gallate and related compounds. Lett Appl Microbiol. 1993; 17:29-35. 
Collins LS, Franzblau SG. Microplate Alamar Blue assay versus BACTEC 460 system for high throughput screening of compounds against Mycobacterium tuberculosis and Mycobacterium avium. Antimicrob. Agents Chemother. 1997; 41:1004-1009.

Duchow S, Blaschek W, Classen B. Influence of plant growth regulators on development and polysaccharide production of cell cultures of Pelargonium sidoides. Afr J Biotechnol. 2014; 13:3244-3251.

Dung NN, Szoki E, Verzar-Petri G. The growth dynamics of callus tissue of root and leaf origin in Datura innoxia Mill. Acta Bot Acad Sci Hung. 1981; 27:325-33.

Katiyar SK, Mukhtar H. Tea antioxidants in cancer prevention. J Cell Biochem. 1997; 27S:59-67.

Kolodziej H. Traditionally used Pelargonium species: Chemistry and biological activity of umckaloabo extracts and their constituents. Curr Topics Phytochem. 2000; 3:77-93.

Kolodziej H, Kayser O. Pelargonium sidoides DC. - Neueste Erkenntnisse zum Phytotherapeutikums Umckaloabo. Z Phytother. 1998; 19:141-151. Cited in: Int J Antimicrob Agents. 2004; 23:613-619.

Kolodziej H, Kayser O, Radtke OA, Albrecht F, Kiderlen AF, Koch E. Pharmacological profile of extracts of Pelargonium sidoides and their constituents. Phytomedicine. 2003; 10:18-24.

Latté KP, Kolodziej H. Antifungal effects of hydrolysable tannins and related compounds on dermatophytes, mould fungi and yeasts. Z Naturforsch(C). 2000; 55:467-472.

Lewu FB, Grierson DS, Afolayan AJ. Extracts from Pelargonium sidoides inhibit the growth of bacteria and fungi. Pharm Biol. 2006; 44:279282.

Lewu FB, Grierson DS, Afolayan AJ. Micropropagation of pelargonium sidoides. Cartrina. 2007; 2:77-81.

Mativandlela SPN, Lall N, Meyer JJM. Antibacterial, antifungal and antitubercular activity of the roots of Pelargonium reniforme (CURT) and Pelargonium sidoides (DC) (Geraniaceae) root extracts. S Afr J Bot. 2006; 72:232-237.

Mativandlela SPV, Meyer JJM, Hussein AA, Lall N Antitubercular Activity of Compounds Isolated from Pelargonium sidoides. Pharm Biol. 2007; 45:645-650.

Mithila J, Murch SJ, KrishnaRaj S, Saxena PK. Recent advances in Pelargonium in vitro regeneration systems. Plant Cell Tissue Organ Cult. $2001 ; 67: 1-9$

Mohammadi M, Alaei M, Bajalan I. Phytochemical screening, total phenolic and flavonoid contents and antioxidant activity of Anabasis setifera and Salsola tomentosa extracted with different extraction methods and solvents. Orient Pharm Exp Med. 2016; 16:31-35.

Moyo M, Finnie JF, Van Staden J. Topolins in Pelargonium sidoides micropropagation: do the new brooms really sweep cleaner? Plant Cell Tiss Organ Cult. 2012; 110:319-327.

Murashige T, Skoog FA. Revised medium for rapid growth and bio assays with tobacco tissue cultures. Physiol Plant. 1962; 15:473-497.

Porter LJ, Hirstich LN, Chan BG. The conversion of procyanidins and prodelphinidins to cyanidin and delphinidin. Phytochemistry. 1986; 25:223-230.

Sgouras D, Maragkoudakis P, Petraki K, Martinez-Gonzalez B, Eriotou E, Michopoulos S, Kalantzopoulos G, Tsakalidou E, Mentis A. In vitro and in vivo inhibition of Helicobacter pylori by Lactobacillus casei strain Shirota. Appl Environ Microbiol. 2004; 70:518-526.

Shabbir G, Anwar F, Sultana B, Khalid ZM, Afzal M, Khan MQ, Ashrafuzzaman M. Antioxidant and antimicrobial attributes and phenolics of different solvent extracts from leaves, flowers and bark of Gold Mohar [Delonix regia (Bojer ex Hook.) Raf.]. Molecules. 2011; 16:7302-7319.

Singleton VL, Orthofer R, Lamuela-Raventos RM. Analysis of total phenols and other oxidation substrates and antioxidants by means of Folin-Ciocalteu reagent. Methods Enzymol. 1999; 299:152-178.

Stankovic MS, Niciforovic N, Mihailovic V, Topuzovic M, Solujic S. Antioxidant activity, total phenolic content and flavonoid concentrations of different plant parts of Teucrium polium L. subsp. Polium. Acta Soc Bot Pol. 2012; 81:117-122.

Sultana B, Anwar F, Ashraf M. Effect of extraction solvent/ technique on the antioxidant activity of selected medicinal plant extracts. Molecules. 2009; 14:2167-2180

Tatiya AU, Tapadiya GG, Kotecha S, Surana SJ. Effect of solvents on total phenolics, antioxidant and antimicrobial properties of Bridelia retusa Spreng. stem bark. Indian J Nat Products Resour. 2011; 2:442-447.

Terrier B, Courtois D, Henault N, Cuvier A, Bastin M, Aknin A, Dubreuil J, Petiard V. Two new disposable bioreactors for plant cell culture: The wave and undertow bioreactor and the slug bubble bioreactor. Biotechnol Bioeng. 2007; 96:914-923.

Vabkova J, Neugebauerova J. Determination of total phenolic content, total flavonoid content and frap in culinary herbs in relation to harvest time. Acta Univ Agric Silvic Mendel Brun. 2012; LX (20):167-172.

Vaghasiya Y, Chanda SV. Screening of methanol and acetone extracts of fourteen indian medicinal plants for antimicrobial activity. Turk J Biol. 2007; 31:243-248.

Wilska-Jeszka J, Stasiak A. 1984. Polyphenol compounds in grain legumes: Bioactive Compounds in Food of Plant Origin. In: Kozłowska H, Fornal J, Zduńczyk Z, eds. Centre for Agrotechnology and Veterinary Sciences. Polish Academy of Sciences, Olsztyn. 126-130.

Wojtania A, Gabryszewska E, Marasek A. Regeneration of Pelargonium $x$ hederaefolium 'Bonete' from petiole explants. Acta Physiol Plant. 2004; 26:255-262.

Yao LH, Jiang YM, Caffin N, D’Arcy B, Datta N, Liu X, Singanusong $\mathrm{R}, \mathrm{Xu} \mathrm{Y}$. Phenolic compounds in tea from Australian supermarkets. Food Chem. 2006; 96:614-620.

Zhou K, Yu L. Effects of extraction solvent on wheat bran antioxidant activity estimation. LWT - Food Sci Technol. 2004; 37:717721

How to cite this article:

Mona MI, Abd El Ghani S, Abd El-Moez SI. Phytochemical Analysis and Antimicrobial Activities of Different Callus Extracts of Pelargonium Sidoides DC. Against Food Borne Pathogenic Bacteria. J App Pharm Sci, 2018; 8(04): 109-118. 